\title{
NUEVO CORONAVIRUS 2019 (COVID-19): Consejos para el odontólogo
}

\author{
New Coronavirus 2019 (COVID-19): Tips for the dentist
}

Se ha generado preocupación mundial por la propagación de un nuevo coronavirus, que apareció en la ciudad china de Wuhan. La Organización Mundial de la Salud (OMS), el día 11 de febrero del 2020, anunció que el nombre oficial de esta enfermedad que está causando el brote del nuevo coronavirus 2019 es COVID-19. Los Centros para el Control y la Prevención de Enfermedades (CDC) están vigilando de cerca este brote de enfermedad respiratoria causada por este nuevo coronavirus. Esta es una situación emergente que está cambiando rápidamente y los $\mathrm{CDC}$ continuarán brindándonos información actualizada a medida que esté disponible, para proteger la salud de las personas, y actúa rápidamente cada vez que hay un problema potencial para la salud pública (1). En total más de 30 países están afectados por el coronavirus COVID-19, por lo que la OMS advierte sobre el riesgo de una pandemia, por lo que ahora es momento de prepararse.

Es probable que este virus haya surgido originalmente de una fuente animal, pero se ha confirmado que puede transmitirse de persona a persona a través de ñas gotitas de flugge (hasta 1 metro de distancia) (2). En relación al diagnóstico, la secuencia genética del COVID-19 se puso a disposición de la OMS el 12 de enero de 2020 y esto ha facilitado a los laboratorios de diferentes países a producir pruebas de diagnóstico de PCR específicas para detectar la nueva infección. El COVID-19 es un $\beta \mathrm{CoV}$ del grupo $2 \mathrm{~B}$ con al menos un $70 \%$ de similitud en la secuencia genética con el SARS-CoV (3).

En las infecciones confirmadas, los síntomas de los casos de enfermedad notificados han variado desde personas levemente enfermas hasta personas gravemente enfermas y que han muerto. Los síntomas pueden incluir: fiebre, tos, dificultad para respirar. Los CDC creen que los síntomas podrían aparecer en tan solo 2 días o hasta 14 días después de la exposición (1).

El nuevo coronavirus (COVID-19) es una amenaza de enfermedad infecciosa nueva y emergente. Todavía hay mucha incertidumbre en torno a su presentación clínica, pero el espectro de la enfermedad puede variar de leve a moderada, a neumonía o infección respiratoria aguda grave. Las personas con COVID-19 "posible" o "confirmado" no deben ser atendidas para recibir atención dental de rutina y se les debe pedir que pospongan su tratamiento hasta la resolución clínica (4).

En la práctica dental general, se recomienda que antes de la cita se puede evitar que las personas con COVID-19 "posible" o "confirmado" lleguen a la consulta. Si una persona asiste a la cirugía dental y que padece síntomas respiratorios y confirma que ha viajado a un área de riesgo, se le debe recomendar que regrese a casa y se comunique con su médico. No deben asistir a su cirugía. Si un caso "posible" o "confirmado" presenta un problema dental agudo que requiere atención dental urgente, el paciente deberá ser derivado para su manejo en un entorno apropiado con medidas de prevención y control de infecciones. Una vez que el individuo ha sido transferido de las instalaciones, no debe usarse la habitación donde fue colocado o aislado. La puerta de la habitación debe permanecer cerrada hasta que se haya limpiado con detergente y desinfectante. Una vez que se 
ha completado este proceso, la sala se puede volver a usar de inmediato. Se debe seguir las instrucciones para la limpieza ambiental después de un caso sospechoso (4). Seguir escrupulosamente todas las normas universales de desinfección y esterilización habituales.

En relación a la prevención, importante porque, no existe una vacuna para prevenir esta cepa del coronavirus. La OMS, recomienda evitar el contacto cercano con personas que sufren infecciones respiratorias agudas. Estas medidas incluyen (5):

- El lavado de manos es clave para la prevención. Se recomienda hacerlo con frecuencia, principalmente, tras el contacto directo con personas enfermas o su entorno.

- Evitar tocarse con las manos sin lavar, los ojos, la nariz y la boca.

- Evitar el contacto cercano con personas enfermas.

- Si está enfermo, quedarse en casa.

- Al toser o estornudar, cubrirse la nariz y la boca con un pañuelo desechable y luego eliminarlo.

- Los objetos y las superficies que se tocan frecuentemente, limpiar y desinfectar usando un producto común de limpieza de uso doméstico.

Los dentistas están sometidos a riesgo de generar aerosoles, por lo que se recomienda el uso de mascarillas FFP2 valvuladas. Algunas recomendaciones acerca de las mascarillas (5):

- Si está usted sano, solo necesita llevar mascarilla si atiende a alguien en quien se sospeche la infección.

- Lleve mascarilla si tiene tos o está estornudando.

- Las mascarillas son eficaces si se combinan con el lavado frecuente de manos con una solución hidroalcohólica o con agua y jabón.

- Si usa una mascarilla quirúrgica habitual (las de tela no se recomiendan), aprenda a usarla y eliminarla correctamente cada 2 horas para evitar su deterioro y pérdida de eficacia.

Como se sabe, no hay ningún tratamiento antiviral específico que se recomiende, por lo que su conocimiento y prevención son fundamentales. Las personas infectadas deben recibir cuidados de apoyo para ayudar a aliviar los síntomas y en casos graves, debe incluir atención médica para apoyar el funcionamiento de los órganos vitales (3).

\section{Sonia Sacsaquispe-Contreras ${ }^{1, a, b, c, c, d}$}

\section{REFERENCIAS BIBLIOGRÁFICAS}

1. Organización Panamericana de la Salud. Actualización Epidemiológica: Nuevo coronavirus (COVID-19) 14 de febrero de 2020. Washington DC: Organización Panamericana de la Salud; 2020.

2. Organización Panamericana de la Salud. Coronavirus disease Covid-19 [internet]. Washington DC: Organización Mundial de la Salud;2020. (Citado el 17 de febrero del 2020) Disponible en: https://www.paho.org/hq/index. php?option $=$ com_content \&view $=$ article $\&$ id $=15696$ :coronavirus-disease-covid-19\&Itemid=4206\&lang=es

3. Instituto Nacional de Salud: Coronavirus. Lima: Instituto
Nacional de Salud; 2020. (Citado el 17 de febrero del 2020) Disponible en: https://dsi.ins.gob.pe/coronavirus/

4. Health Protection Scotland. COVID-19 Advice for Dental Teams. National Services Scotland. Glasgow: Health Protection Scotland; 14 February 2020. (Citado el 17 de febrero del 2020) Disponible en: https://www.hps.scot.nhs. uk/a-toz-of-topics/novel-coronavirus-2019-ncov/

5. Centros para el Control y la Prevención de Enfermedades. Coronavirus 2019 (COVID-19). Washington DC: Centros para el Control y la Prevención de Enfermedades; 2019. (Citado el 17 de febrero del 2020) Disponible en:https://www. cdc.gov/coronavirus/2019-ncov/index-sp.html

International Association of Oral Pathologists. Sheffield, Inglaterra.

Cirujano Dentista.

Especialista en Medicina y Patología Oral.

Magister en Estomatología.

Doctor en Estomatología. 